\title{
Reflection on International Training for High-speed Railway Going Global
}

\author{
Jing Jin ${ }^{\mathrm{a}}$, Kefei Zhu ${ }^{\mathrm{b}}$ and Yu Yang \\ China Academy of Railway Sciences, Beijing 100081, China \\ jinjing@rails.cn, bhukf@rails.cn, cyangyu@rails.cn
}

Keywords: International training, standard, railway, going global.

\begin{abstract}
Under the background of "Belt and Road Initiative", railway, especially high-speed railway as an important part of infrastructure connectivity, are welcomed by countries along "Belt and Road”. Along the export of railway infrastructure and facility, education export plays an crucial role for promotion of China railway technology and standards. This paper analyzes the existing high-speed railway training mode and resources, summarizes the existing international and domestic standard and procedure for technical training, and then puts forward with the proposals for international to foreign railway technological and management personnel of targeted country.
\end{abstract}

\section{Introduction}

Railway personnel training are carried through three levels including CHINA RAILWAY, Railway Administration and railway depot. Railway personnel can be divided into two categories of technical personnel (worker) and management and professional technical personnel (cadre). CHINA RAILWAY (former Ministry of Railway) as the management and operation undertaking of China railway system, issues a series of qualification standard for key front-line professional technical jobs such as Entrance Management Regulation for Major High-speed Railway Operation Work and Major High-speed Railway Operation Work Standard to ensure the safety operation of high-speed railway including qualification requirement of holding the post, competency requirement, and training standard. The training was divided into theoretical training (half of the training time) and practical training (half of the training time), which covers the basic knowledge, practical training and emergence management; while the qualification test will be carried at the interval of three years. However, when China railway going global, the related training system needs to be adapted to local condition and adjusted. This paper analyses existing standard and guidelines for training, and then puts forward with suggestion for international training for highspeed railway going global.

\section{Research on international standards for training}

ISO issued ISO10015: Quality Management_-Guidelines for Training in 1999, which is the newest guidance for training standard in human resource. The State Bureau of Quality and Technical Supervision issued the equivalent Chinese standard. The guideline divides training into four periods including demand analysis, training design and planning, implementation of training, and evaluation of training result. 


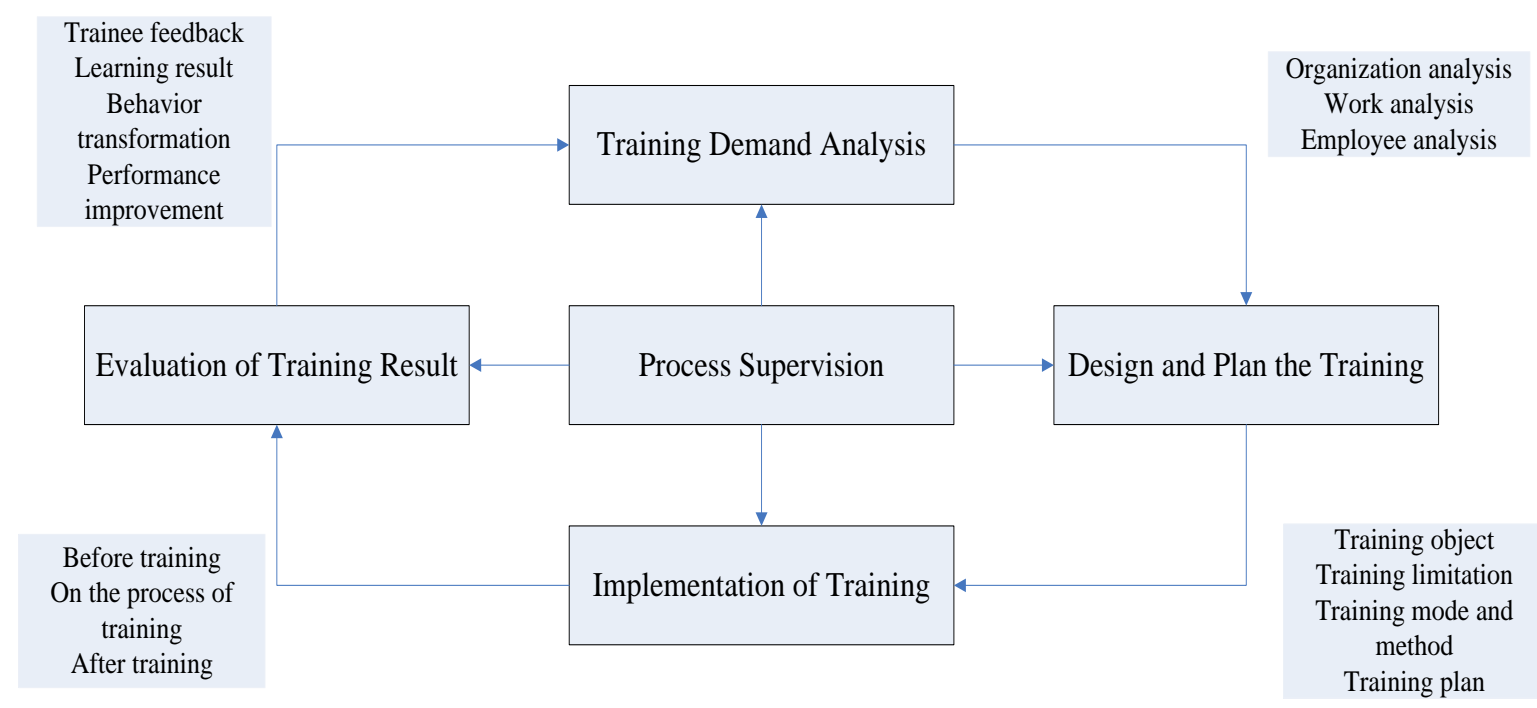

Fig. 1 ISO 10015 Model: Training Circulation Diagram

For demand analysis, the purpose is to find the gap between current capability and required capability of the trainee, and then decide the training needed to fill in the gap and draft the document of training demand. During this process, demand including demand for training task, demand for position, demand for employee capability, demand for employee personal development, etc. should be analyzed, and organization need including achievement of performance target and company strategy also should be taken into consideration. In order to precisely define the capability gap, capability evaluation for trainee, and necessary internal and external qualification test need to be carried out.

For training design and planning, training modes including on-site or off-site lesson, seminar, apprentice, guidance during the work, self-learning, on-line learning need to be selected. Training plan needs to consider the target and requirement of organization, training requirement, training purpose, financial requirement and the trainee in order to decide the training schedule and resources (including training material and teachers) allocation.

For implementation of training, before the training, demand analysis and capability evaluation need to be carried out with aim of opening an negotiation platform between the trainer and trainee. On the process of training, site for training, training tools, training material and software, and arrangement of accommodation are appropriately provides. Trainee should have the opportunity to practice and give feedback about the training through the process. After training, the feedback from trainee will be collected and analyzed for improvement of next training.

For evaluation of training result, trainee satisfaction, achievement of knowledge, skill and behavior mode, work performance, satisfaction of trainee's leader, affect on the organization, and supervision of training procedure need to be evaluated. Short-term and long-term evaluation need to be combined; while short -term evaluation emphasis on feedback of allocation of teaching resource and knowledge acquired and skill promoted from training. Long-term evaluation emphasis on work performance and productivity improvement.

\section{Research on domestic standards and guideline for training}

\subsection{China's technical talents cultivation standard}

Ministry of Human Resources and Social Security issued the Guideline for National Technical Personnel Cultivation Standard in 2013 in order to build cultivation system of technical talents centering on comprehensive professional skill and improve overall quality of technical personnel. The technical talents cultivation standard includes cultivation purpose, cultivation requirement, cultivation mode, cultivation condition and cultivation quality. 


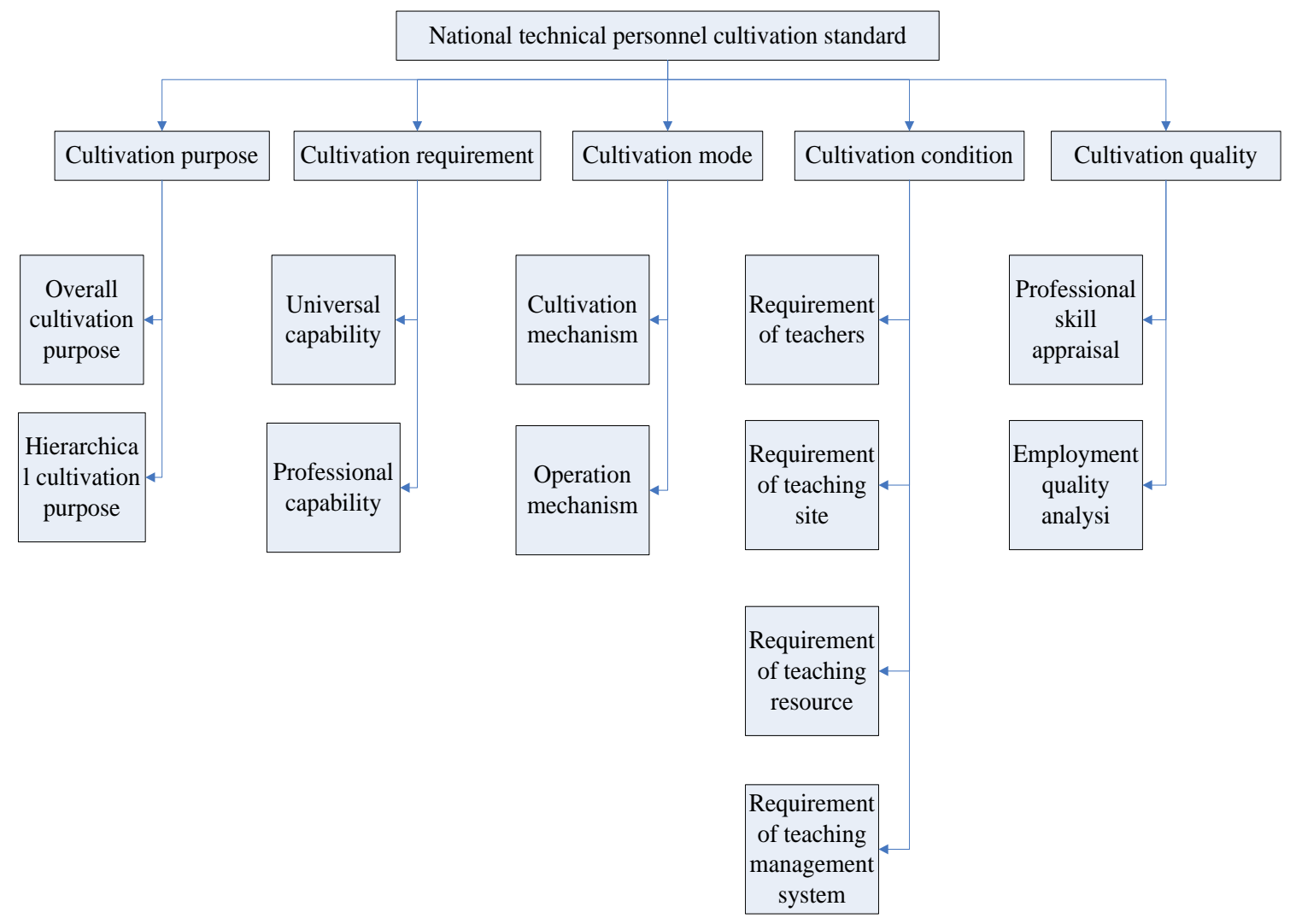

Fig. 2 Structure for national technical personnel cultivation standard

According to China technical talents cultivation standard, technical personnel are divided into three categories of potential technician, middle-level technical personnel, senior technical personnel with different cultivation objectives. One characteristics of this standard is that it emphasis on description and explanation of typical work task with the aim of analyzing the procedure, standard and requirement of different links, the cooperative relation between employees and different departments and also the capability requirement of employee.

\subsection{Foreign aid training}

Foreign aid training led by Ministry of Commerce, is an governmental level human resource development project for under-developed or developing countries, and can be mainly divided into advanced study and training for officials, technical training, short-term personnel exchange, and etc. Foreign aid training is taken as an reference for international training, especially to developing and underdeveloped countries.

Through long period of training experience accumulation, a systematic training regulation and standard are established including time arrangement between lecture (40\%-50\%) and on-site technical visit, qualification for company and requirement for personnel to undertake foreign training, requirement for teachers (should have senior academic title or official with section chief rank, familiar with the topic, and can give lessons in English), spending standard for training, and procedure for training process, with a whole set of standardized document to record the training process.

\section{Speculation on training standard for railway going global projects}

Railway operation requires support of large amount of railway technical and management personnel. According to UIC statistics of high-speed railway planing of different countries, mostly centering on Asia countries, especially along "Belt and Road" area. Currently, training for international railway projects is undertaken by different transportation universities, railway vocational schools and railway training bases lacking of universal standard to give full play to the role of training. This paper raises four proposals for international training: 
1) Moderate advancement of planning

Training for international projects should accompany the life-circle of railway projects, and the planning should be ahead of the implementation of railway projects with different purposes for different stages. Technical exchange should be emphasized as an important form of training to facilitate the smooth implementation of railway projects.

2) Scientific training method

Training method includes technical lecture, workshop and seminar, technical visit, practical training and internship should be balanced with the adoption of network training and virtual reality technology to increase training efficiency and reduce the cost.

3) Systematic allocation of resource

The life circle of an international railway project covers feasibility study, railway surveying and planning, railway construction and railway operation and maintenance, involving different disciplines and majors, which indicates that it is almost impossible to carry out the whole training within one university or vocational school. Therefore, integration and allocation of training resources is an necessity

4) Hierarchic demand investigation

Adopting three hierarchic analyzing method proposed by McGehee and Thayer, demand analysis for international railway project can be carried through three levels: talents demand from the perspective of project for short term, talents demand from the perspective of industry for middle term, talents demand from the perspective of infrastructure construction to promote national economic growth for long term. Middle term training also involve diploma education (undergraduate and graduate diploma) for department managers or high-level management and technical officials, while long term training includes training for the teaching staff and senior R \& D personnel to promote railway education localization and independent research and development.

\section{Summary}

International training as an booster for going global projects, should be indicated in going global strategy, as a soft power to promote China technology and standard. Currently, for government and enterprises, they emphasis too much on products, facilities and technical standard, but overlook the training, especially in forms of technical communication and exchange to influence the policymakers of foreign countries. Therefore, international training for sustaining international railway project should be specially focused on, and related training standard should be established to regulate the procedure for training and improve training efficiency.

\section{Acknowledgements}

Supported by Foundation project of China Academy of Railway Sciences "Talents Cultivation Mode and Implementation Plan for Foreign Management and Technical Personnel Adapting to China High-speed Railway Going Global”, Project No.: 2016YJ150.

\section{References}

[1] Song Yisi. Constructing New Model for ISO 10015 International Training Standard System. Economist, 2007, (2): 218-219

[2] Xu Chunlie, Yu Zhenyu, International Standard for Human Resource Training_-ISO 10015 International Training Management Standard. China Power Education, 2006, (6): 37-40

[3] Wang Lin, Peng Qiyuan, Lina, Reflection on Curriculum Design for China High-speed Railway Going Global. Journal of Social Sciences of Southwest Jiaotong University, 2015, 16(3)

[4] Fan Xiaoyu, Chen Jianguang, Study of International Training Standard for Constructing Scientific Training System. Journal of Adult Education School for University of Hebei, 2008, 10(2): 51-52 